Article

\title{
Optimization of Induction Motor Equivalent Circuit Parameter Estimation Based on Manufacturer's Data
}

\author{
Saleh A. Al-Jufout ${ }^{1, *}$, Wasseem H. Al-rousan ${ }^{2}$ and Caisheng Wang ${ }^{2, *}$ \\ 1 Electrical Power Engineering and Mechatronics Department, Tafila Technical University, Tafila 66110, Jordan \\ 2 Electrical and Computer Engineering Department, Wayne State University, Detroit, MI 48202, USA; \\ wrousan@wayne.edu \\ * $\quad$ Correspondence: drjufout@ttu.edu.jo (S.A.A.-J.); cwang@wayne.edu (C.W.); \\ Tel.: +962-799-027-877 (S.A.A.-J.); Tel.: +1-313-577-8074 (C.W.)
}

Received: 6 June 2018; Accepted: 5 July 2018; Published: 8 July 2018

\begin{abstract}
This paper presents a two-stage optimization of the parameters of a seven-parameter equivalent circuit of three-phase induction motor. The initial parameters of this equivalent circuit are estimated by a method called the Engineering Method using the data given in the manufacturer's data sheet. The two-stage parameter optimization procedure was developed to minimize the errors between the estimated and the actual values in motor torque and current. In the first stage, the method is targeted to optimize the parameters of the stator only. The second stage, if necessary, aims at optimizing the rotor-circuit parameters. Normalized least squares method is used to formulate the optimization problem. An objective function is established to minimize the errors between the calculated starting torque and current and the pullout torque and the given values in the manufacturer's data sheet. The model parameters of ten industrial induction motors are estimated without and with optimization. The obtained results are compared with the Engineering Method and the actual manufacturer's data to verify the effectiveness of the proposed method.
\end{abstract}

Keywords: equivalent circuit; induction motor; manufacturer's data; optimization; parameters estimation; squirrel cage

\section{Introduction}

Due to its reliability and low cost, induction motors are the most widely used motors in most industrial applications. Performance analysis of an induction motor and its behavior prediction during faults and different normal operating regimes require the representation of the motor by an adequate mathematical model [1-4]. The accuracy of this analysis depends on the adopted equivalent circuit in the mathematical model of the induction motor.

According to the IEEE standard 112 ${ }^{\mathrm{TM}}-2004$ [5], which is a revision of the IEEE standard 112-1996, the test procedure for poly-phase induction motors and generators include (1) a no-load test to determine the core, windage and friction losses; (2) a load test to determine the efficiency, power factor, speed, current, and temperature rise; (3) a dc test to measure the stator resistance; and (4) a locked rotor test to determine the total leakage reactance. However, at the design level of a power supply system with induction motors or when there is no means (or it is too expensive) to perform these tests on existing motors, the parameters of the equivalent circuit of the motor can be estimated from the manufacturer's data sheet [6-17].

In [6], the authors proposed an iterative method for equivalent circuit parameter identification using the nameplate data, which includes the rated power, voltage, efficiency, power factor, speed and number of poles, NEMA design type, and code letter. The authors in [7] used speed, rated torque, starting torque, efficiency, and power factor values at $100 \%, 75 \%$ and $50 \%$ of the rated load to estimate 
the parameters of the equivalent circuit of the induction motor. In [8], a method was proposed to estimate the induction motor model parameters using the nameplate data, the ratio of starting torque to the full load torque, and the power factor and efficiency at $100 \%$ and $50 \%$ of the rated full load. In [9] and [10], a detailed two-part study was performed on induction motor modeling and model parameters estimation based on the electrical and geometrical data generally given after the electromagnetic design. However, the equivalent circuit of the rotor of squirrel-cage motors in $[6,10]$ is modeled by one resistive-inductive branch that does not accurately reflect the non-uniformity distribution of the current in the rotor bars of squirrel-cage motors. In addition, some of these methods require data at operating conditions other than $100 \%$ of the rated load. In [11], the researchers presented a methodology for determining the equivalent circuit parameters for an induction machine by estimating the rotor parameters as a function of slip. In [12] the authors suggested a method for obtaining the circuit parameters of National Electrical Manufacturers Association (NEMA) design A and B induction motors. Their method was based on the formulation of a set of nonlinear equations derived from the induction machine equivalent circuit with the manufacturers' data. Another parameter identification method was proposed in [13] using the results obtained through varying frequency tests.

Enhancement of the starting characteristics in squirrel-cage induction motors is achieved by the double-cage or deep-bar design of the rotor bars. In these bars, the current density is not uniform due to the skin effect. The skin effect causes variations in the resistance and reactance of the equivalent circuit of the rotor bars [10,14]. An eight-parameter equivalent circuit was proposed in [15] to represent the rotor by series inductance connected in parallel with two parallel-connected resistive-inductive branches. A seven-parameter equivalent circuit was presented in [16] to represent the rotor by two parallel-connected resistive-inductive branches. It was reported in the paper that the resistance of the stator is the least significant parameter in the parameters estimation. A method called the "Engineering Method" was proposed in [17] to determine the parameters of a seven-parameter equivalent circuit model of the induction motor. According to this engineering method, the error when comparing the data provided by the manufacturer is about $1-3 \%$.

This paper aims at optimizing the initial model parameters obtained via the Engineering Method to minimize the errors between the model predictions and the manufacturer's data. The optimized parameters obtained through the proposed two-stage optimization method better match the manufacturer's data than those developed in the previous works. The rest of this paper is structured as follows: An introduction to different equivalent circuits of the induction motor and methods of model parameters identification is given in Section 1; the Engineering Method developed in [17] is introduced and summarized in Section 2; the proposed two-stage parameters optimization procedure is described in Section 3; the results are given and discussed in Section 4, followed by the concluding remarks in Section 5.

\section{Engineering Method for Parameter Estimation}

The Engineering Method is a method proposed in [17] to estimate the per-unit parameters of a seven-parameter equivalent circuit model of the induction motor, from the data given in the manufacturer's data sheet. The seven parameters of this model are shown in Figure 1 and explained below. The equivalent circuit of the rotor of the squirrel-cage motor is modeled by two parallel connected resistive-inductive branches 1 and 2. The superscripts (1) and (2) are used to denote branches 1 and 2, respectively. This method requires the following data: the rated slip or speed, power factor, efficiency, the ratios of the starting and pullout torques to the full load torque, and the ratio of the starting current to the rated current. To evaluate the parameters in actual values, if needed, the rated voltage and power of the motor will be required as well. 


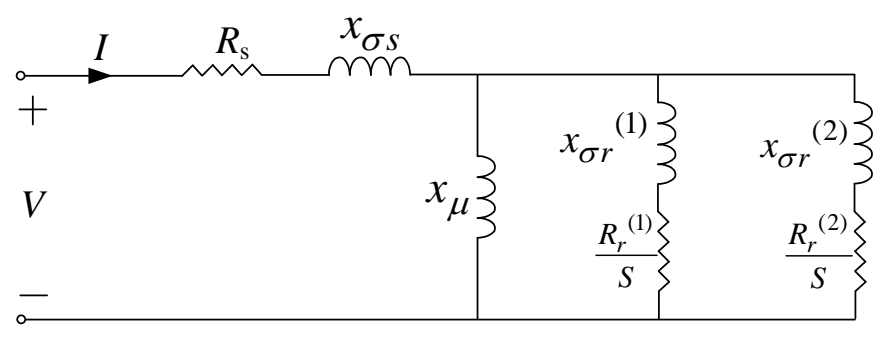

Figure 1. Equivalent circuit for the three-phase induction motor.

According to [17], the Engineering Method for parameter identification of the per unit equivalent circuit of the induction motor is given as follows:

1. The resistance $\left(R_{S}\right)$ and leakage inductance $\left(x_{\sigma s}\right)$ of the stator are estimated as:

$$
\begin{gathered}
R_{s} \approx S_{\text {rated }}, \\
x_{\sigma s}=\frac{1}{(2 \sim 3) K_{i_{\text {start }}}},
\end{gathered}
$$

where $\left(S_{\text {rated }}\right)$ is the rated slip of the machine and $\left(K_{i_{\text {start }}}\right)$ is the ratio of the starting current over the rated current. In [17], the authors calculated the leakage reactance of the stator as one third of the input reactance of the motor, while in [18], the authors stated that the leakage reactance of the stator can be estimated as half of the input reactance.

2. Since the core loss is not represented in the model under investigation [17], the values of the given efficiency and power factor are corrected as follows:

$$
\begin{gathered}
\eta^{\prime}=1-R_{s}-\frac{\eta \times \cos \phi \times S_{\text {rated }}}{1-S_{\text {rated }}}, \\
\cos \phi^{\prime}=\frac{\eta \times \cos \phi}{\eta^{\prime}},
\end{gathered}
$$

where $\eta$ and $\cos \phi$ are the motor efficiency and power factor at full load, respectively. In [18] and [19], the authors proposed a nine-parameter equivalent circuit that does not ignore the core loss in the machine. In that case, this correction step is not needed.

3. The reactance of the magnetization branch $\left(x_{\mu}\right)$ is calculated as follows:

$$
x_{\mu}=\frac{1}{i_{\mu}}-x_{\sigma s}
$$

where the magnetization current $\left(i_{\mu}\right)$ is calculated by:

$$
i_{\mu}=\sqrt{1-\cos \phi^{\prime 2}}-\left(K_{\tau_{\max }}-\sqrt{K_{\tau_{\max }^{2}}^{2}-1}\right) \times \cos \phi^{\prime},
$$

$K_{\tau_{\max }}$ in (6) is the ratio of the pullout torque to the full load torque given in the manufacturer's data sheet.

4. The input resistance and reactance, at the rated slip $\left(S_{\text {rated }}\right)$ and the starting slip $(\mathrm{S}=1)$, are estimated as follows:

$$
\begin{gathered}
R_{\text {input }}^{S_{\text {rated }}}=\cos \phi^{\prime}, \\
x_{\text {input }}^{S_{\text {rated }}=\sin \phi^{\prime}}=\sqrt{1-\cos \phi^{\prime 2},}
\end{gathered}
$$




$$
\begin{gathered}
R_{\text {input }}^{S=1}=R_{S}+\frac{K_{\tau_{\text {start }}}^{\text {corr. }} \eta^{\prime} \times \cos \phi^{\prime}}{\left(K_{i_{\text {start }}^{\text {corr }}}^{\text {con }}\right)^{2} \times\left(1-S_{\text {rated }}\right)} \\
x_{\text {input }}^{S=1}=\sqrt{\frac{1}{\left(K_{i_{\text {start }}^{\text {corr. }}}\right)^{2}}-\left(R_{\text {input }}^{S=1}\right)^{2}}
\end{gathered}
$$

To increase the accuracy, the ratio of the starting torque to the full load torque $\left(K_{\tau_{\text {start }}}\right)$ and the ratio of the starting current to the rated current $\left(K_{i_{\text {start }}}\right)$ are corrected as:

$$
\begin{aligned}
& K_{i_{\text {start }}}^{\text {corr. }}=0.99 K_{i_{\text {start }}}, \\
& K_{\tau_{\text {start }}}^{\text {corr. }}=1.01 K_{\tau_{\text {start }}},
\end{aligned}
$$

5. The conductance and susceptance of the rotor, at the rated slip $\left(S_{\text {rated }}\right)$ and the starting slip $(\mathrm{S}=1)$, are determined as follows:

$$
\begin{gathered}
G_{r}^{S_{\text {rated }}}=\frac{R_{\text {input }}^{S_{\text {rated }}}-R_{S}}{\left(R_{\text {input }}^{S_{\text {rated }}}-R_{S}\right)^{2}+\left(x_{\text {input }}^{S_{\text {rated }}}-x_{\sigma S}\right)^{2}}, \\
B_{r}^{S_{\text {rated }}}=\frac{x_{\text {input }}^{S_{\text {rated }}}-x_{\sigma S}}{\left(R_{\text {input }}^{S_{\text {rated }}}-R_{S}\right)^{2}+\left(x_{\text {input }}^{S_{\text {rated }}}-x_{\sigma S}\right)^{2}}-\frac{1}{x_{\mu}}, \\
G_{r}^{S=1}=\frac{R_{\text {input }}^{S=1}-R_{S}}{\left(R_{\text {input }}^{S=1}-R_{S}\right)^{2}+\left(x_{\text {input }}^{S=1}-x_{\sigma S}\right)^{2}} \\
B_{r}^{S=1}=\frac{x_{\text {input }}^{S=1}-x_{\sigma S}}{\left(R_{\text {input }}^{S=1}-R_{S}\right)^{2}+\left(x_{\text {input }}^{S=1}-x_{\sigma S}\right)^{2}}-\frac{1}{x_{\mu}}
\end{gathered}
$$

6. The resistance and the leakage reactance of the first rotor-circuit branch are calculated as:

$$
\begin{aligned}
& R_{r}^{(1)}=\frac{G_{r}^{S_{\text {rated }}}}{\left(G_{r}^{S_{\text {rated }}}\right)^{2}+\left(B_{r}^{S_{\text {rated }}}\right)^{2}} S_{\text {rated }} \\
& x_{\sigma r}^{(1)}=\frac{B_{r}^{S_{\text {rated }}}}{\left(G_{r}^{S_{\text {rated }}}\right)^{2}+\left(B_{r}^{S_{\text {rated }}}\right)^{2}} S_{\text {rated }}
\end{aligned}
$$

7. The resistance and leakage reactance of the second rotor-circuit are calculated as:

$$
\begin{aligned}
& R_{r}^{(2)}=\frac{G_{r}^{(2)}}{\left(G_{r}^{(2)}\right)^{2}+\left(B_{r}^{(2)}\right)^{2}}, \\
& x_{\sigma r}^{(2)}=\frac{B_{r}^{(2)}}{\left(G_{r}^{(2)}\right)^{2}+\left(B_{r}^{(2)}\right)^{2}},
\end{aligned}
$$

where the conductance $\left(G_{r}^{(2)}\right)$ and susceptance $\left(B_{r}^{(2)}\right)$ of the second rotor circuit, at starting slip $(\mathrm{S}=1)$, are determined as follows:

$$
G_{r}^{(2)}=G_{r}^{S=1}-\frac{R_{r}^{(1)}}{\left(R_{r}^{(1)}\right)^{2}+\left(x_{\sigma r}^{(1)}\right)^{2}},
$$




$$
B_{r}^{(2)}=B_{r}^{S=1}-\frac{x_{\sigma r}^{(1)}}{\left(R_{r}^{(1)}\right)^{2}+\left(x_{\sigma r}^{(1)}\right)^{2}},
$$

To validate the above summarized algorithm, the authors in [17] calculated the stator current and torque at different values of slip (rated, critical and starting) and compared them to those values given in the data sheet as follows:

$$
\begin{gathered}
K_{i}^{\text {calc. }}(S)=\frac{1}{\sqrt{\left(R_{\text {input }}^{(S)}\right)^{2}+\left(x_{\text {input }}^{(S)}\right)^{2}}}, \\
K^{\text {calc. }}(S)=i_{S}^{2}(S)\left(R_{\text {input }}^{(s)}-R_{S}\right) \frac{1-S_{\text {rated }}}{\eta^{\prime} \cdot \cos \phi^{\prime}},
\end{gathered}
$$

The critical slip $\left(S_{c r}\right)$ is calculated by:

$$
S_{c r}=\frac{K_{\tau_{\max }} \pm \sqrt{K_{\tau_{\max }}^{2}-1-k_{2}\left(1-K_{\tau_{\max }}\right)}}{1+k_{2}\left(1-K_{\tau_{\max }}\right)} S_{\text {rated }},
$$

where the coefficients of $k_{1}$ and $k_{2}$ can be calculated as:

$$
\begin{aligned}
& k_{1}=1+\frac{x_{\sigma s}}{x_{\mu}}, \\
& k_{2}=\frac{2 R_{s} S_{\text {rated }}}{k_{1} R_{r}^{(1)}},
\end{aligned}
$$

Since there are two values for the critical slip calculated by (25), the extraneous value is excluded.

In this paper, the algorithm of the Engineering Method has been realized using MATLAB. A comparison of the manufacturer's ratios of the starting and pullout torques, and the starting current with those calculated by the Engineering Method for different motors are shown in Table 1 . The first record for DAZO-1569-8/10 is given as an example in [17], where the percentage errors are in the range of $1-3 \%$. The other nine motors were selected randomly from different tables with different technical specifications, such as rated speed, rated power, power factor and efficiency. The data sheets of these induction motors, which are listed in Table 1, are available in [20] and [21]; Table A1 in Appendix A summarizes the technical specifications of these motors.

As shown in Table 1, the errors between the calculated values and the real manufacturer's values for the motors with numbers $2,4,5$ and 10 are about $1 \%$; thus, for these motors, the parameters of the equivalent circuit determined by the Engineering Method may be sufficient for engineering calculations.

However, when applying this method to estimate the parameters of the equivalent circuits for other motors (with numbers 3, 6, 7, 8 and 9), it is found that the error might be more than the acceptable value for engineering calculations. For instance, the error of $\left(K_{\tau_{\max }}\right)$ for $1 \mathrm{LA} 8455-8 \mathrm{AD}$ is over $9 \%$ and over 7\% for 1PQ8 458-8PD, as shown in Table 1 . Thus, it is necessary to tune the model parameters to reduce the errors. To achieve this goal, a parameter optimization procedure for the Engineering Method is proposed in Section 3. 
Table 1. Comparison of the manufacturers' ratios of the starting and pullout torques, and the starting current with those calculated by the engineering method.

\begin{tabular}{|c|c|c|c|c|c|c|c|c|}
\hline \multirow{2}{*}{ No. } & \multirow{2}{*}{ Motor Type } & \multirow{2}{*}{ Source of Data } & \multirow{2}{*}{$K_{i_{\text {start }}}$} & \multirow{2}{*}{$K_{\mathbf{\sigma}_{\text {start }}}$} & \multirow{2}{*}{$K_{\boldsymbol{\sigma}_{\max }}$} & \multicolumn{3}{|c|}{ Error, \% } \\
\hline & & & & & & $K_{i_{\text {start }}}$ & $K_{\mathbf{\sigma}_{\text {start }}}$ & $K_{\boldsymbol{\Phi}_{\max }}$ \\
\hline \multirow{2}{*}{1.} & \multirow{2}{*}{ DAZO-1569-8/10 } & Data sheet & 5.500 & 0.800 & 2.700 & \multirow{2}{*}{1.000} & \multirow[b]{2}{*}{1.000} & \multirow{2}{*}{2.991} \\
\hline & & Engineering Method & 5.445 & 0.808 & 2.619 & & & \\
\hline \multirow[b]{2}{*}{2.} & \multirow[b]{2}{*}{ 1LA8 317-2AC } & Data sheet & 7.000 & 1.800 & 2.800 & \multirow[b]{2}{*}{1.000} & \multirow{2}{*}{1.000} & \multirow{2}{*}{1.007} \\
\hline & & Engineering Method & 6.930 & 1.818 & 2.828 & & & \\
\hline \multirow{2}{*}{3.} & \multirow{2}{*}{ 1LA8 315-6AB } & Data sheet & 6.500 & 2.000 & 2.500 & \multirow{2}{*}{1.000} & \multirow{2}{*}{1.000} & \multirow{2}{*}{3.346} \\
\hline & & Engineering Method & 6.435 & 2.020 & 2.584 & & & \\
\hline \multirow[b]{2}{*}{4.} & \multirow{2}{*}{ 1PQ8 357-2PC } & Data sheet & 6.500 & 1.800 & 2.600 & \multirow[b]{2}{*}{1.000} & \multirow[b]{2}{*}{1.000} & \multirow[b]{2}{*}{0.703} \\
\hline & & Engineering Method & 6.435 & 1.818 & 2.618 & & & \\
\hline \multirow{2}{*}{5.} & \multirow{2}{*}{ 1PQ8 407-4PB } & Data sheet & 6.800 & 1.900 & 2.700 & \multirow{2}{*}{1.000} & \multirow{2}{*}{1.000} & \multirow{2}{*}{0.790} \\
\hline & & Engineering Method & 6.732 & 1.919 & 2.721 & & & \\
\hline \multirow[b]{2}{*}{6.} & \multirow{2}{*}{ 1LA8 455-8AD } & Data sheet & 7.000 & 1.200 & 2.700 & & & \\
\hline & & Engineering Method & 6.930 & 1.212 & 2.946 & 1.000 & 1.000 & 9.113 \\
\hline & & Data sheet & 6.800 & 0.900 & 2.500 & & & \\
\hline 7. & 1LA8 458-4AD & Engineering Method & 6.732 & 0.909 & 2.662 & 1.000 & 1.000 & 6.463 \\
\hline & & Data sheet & 6.500 & 1.200 & 2.500 & & & \\
\hline 8. & 1PQ8 453-6PD & Engineering Method & 6.435 & 1.212 & 2.644 & 1.000 & 1.000 & 5.779 \\
\hline 0 & $1 \mathrm{PO} 8$ 458-8PD & Data sheet & 6.500 & 1.000 & 2.600 & & & \\
\hline 9. & TPQ8 458-8PD & Engineering Method & 6.435 & 1.010 & 2.800 & 1.000 & 1.000 & 7.710 \\
\hline & & Data sheet & 5.300 & 0.900 & 2.300 & & & \\
\hline 10. & 2А3M-2500/6000YXL4 & Engineering Method & 5.247 & 0.909 & 2.294 & 1.000 & 1.000 & 0.274 \\
\hline
\end{tabular}

\section{Proposed Optimization Procedure}

This paper aims at optimizing the Engineering Method summarized in Section 2 to minimize the errors shown in Table 1. The optimization procedure is proposed to be performed in two stages. In the first stage, the optimization is carried out for the stator parameters only; rewriting (1), (2), (11) and (12) yields:

$$
\begin{gathered}
R_{S}=C_{1} S_{\text {rated }}, \\
x_{\sigma S}=\frac{1}{C_{2} K_{i_{\text {start }}}}, \\
K_{i_{\text {start }}}^{\text {corr. }}=C_{3} K_{i_{\text {start }}}, \\
K_{\tau_{\text {start }}}^{\text {corr. }}=C_{4} K_{\tau_{\text {start }}},
\end{gathered}
$$

The coefficients $\left(C_{1}, C_{2}, C_{3}\right.$ and $\left.C_{4}\right)$ are bounded as follows:

$$
\left\{\begin{aligned}
0.9 & \leq C_{1} \leq 1.1 \\
2 & \leq C_{2} \leq 3 \\
0.99 & \leq C_{3} \leq 1.01 \\
0.99 & \leq C_{4} \leq 1.01
\end{aligned}\right.
$$

The reasons for selecting those boundaries are as follows:

$C_{1}$ : the Engineering Method claims that $R_{S}$ is approximately equal to the rated slip. For practical calculations, it is assumed to be equal. We represent this approximation by $+-1 \%$.

$C_{2}$ : many researchers $[17,18]$ claim that the leakage reactance of the stator is one third to half of the input impedance at starting.

$C_{3}$ and $C_{4}$ : the Engineering Method claims that $C_{3}$ is 0.99 and $C_{4}$ is 1.01 to correct the starting current and torque ratios at starting. In this paper, we assumed them to range from 0.99 to 1.01. Results, in this paper, show that this correction is not necessary in most cases.

The goal of the model parameter optimization is to minimize the errors between the calculated values and the real manufacturer values. In this study, the focus is given to the starting current ratio $\left(K_{i_{\text {start }}}\right)$, starting torque ratio $\left(K_{\tau_{\text {start }}}\right)$, and the pull-out torque ratio $\left(K_{\tau_{\max }}\right)$. Define 


$$
\begin{aligned}
& f_{1}(x)=\left(\frac{K_{i_{\text {start }}}-K_{i_{\text {start }}}^{\text {calc. }}}{K_{i_{\text {start }}}}\right)^{2}, \\
& f_{2}(x)=\left(\frac{K_{\tau_{\text {start }}}-K_{\tau_{\text {start }}}^{\text {calc. }}}{K_{\tau_{\text {start }}}}\right)^{2}, \\
& f_{3}(x)=\left(\frac{K_{\tau_{\max }}-K_{\tau_{\max }}^{\text {calc. }}}{K_{\tau_{\max }}}\right)^{2},
\end{aligned}
$$

where $x=\left[\begin{array}{llll}C_{1} & C_{2} & C_{3} & C_{4}\end{array}\right]^{\prime}$. The starting ratios are calculated by (23) and (24) at $S=1$. In addition, the pullout torque ratio is calculated by (24) at the critical slip.

Taking into account (30), the parameter optimization problem can be formulated as follows:

$$
\min \sum_{i=1}^{3} \lambda_{i} f_{i}
$$

Subject to constraints in (30).

where $\lambda_{i}, i=1,2,3$ are the weight factors. For the optimization process, the weight factors in an objective function are of a great importance and should be chosen carefully. For the case in this paper, it is desirable to give each of the torque-slip and current-slip characteristics equal weights [15]. In other words, $\lambda_{i}=1, i=1,2,3$ for the study in this paper.

In this paper, MATLAB, based on the default interior-point algorithm, is used to solve the nonlinear optimization problem with bounded constraints. The procedure used in the first stage of optimization is summarized in Algorithm 1.

Algorithm 1: First Stage of Optimization.

Step 1: Import induction machine parameters from the manufacturer's data sheet

Step 2: Obtain the parameters of the equivalent circuit of the machine using the Engineering Method

Step 3: Minimize the error functions $f_{1}, f_{2}$ and $f_{3}$, and iterate until the optimization criterion is met

Step 4: Obtain the optimized values for the independent variables $C_{1}, C_{2}, C_{3}$ and $C_{4}$

Step 5: Recalculate the parameters of the equivalent circuit using the optimized values of $C_{1}, C_{2}, C_{3}$ and $C_{4}$

\begin{tabular}{|c|c|c|c|c|c|c|c|c|c|}
\hline \multirow{2}{*}{ No. } & \multirow{2}{*}{ Motor Type } & \multirow{2}{*}{ Method } & \multirow{2}{*}{$\mathrm{C}_{1}$} & \multirow{2}{*}{$\mathrm{C}_{2}$} & \multirow{2}{*}{$\mathrm{C}_{3}$} & \multirow{2}{*}{$\mathrm{C}_{4}$} & \multicolumn{3}{|c|}{ Error, \% } \\
\hline & & & & & & & $K_{i_{\text {start }}}$ & $K_{\boldsymbol{\Phi}_{\text {start }}}$ & $K_{\boldsymbol{\sigma}_{\max }}$ \\
\hline \multirow[b]{2}{*}{1.} & \multirow{2}{*}{ DAZO-1569-8/10 } & Engineering & 1.000 & 3.000 & 0.990 & 1.010 & 1.000 & 1.000 & 2.991 \\
\hline & & 1st optimization stage & 0.900 & 2.002 & 1.005 & 1.000 & 0.510 & 0.030 & 1.020 \\
\hline \multirow[b]{2}{*}{2.} & \multirow{2}{*}{ 1LA8 317-2AC } & Engineering & 1.000 & 3.000 & 0.990 & 1.010 & 1.000 & 1.000 & 1.007 \\
\hline & & 1st optimization stage & 1.100 & 2.995 & 0.998 & 1.000 & 0.240 & 0.020 & 0.800 \\
\hline \multirow[b]{2}{*}{3.} & \multirow{2}{*}{ 1LA8 315-6AB } & Engineering & 1.000 & 3.000 & 0.990 & 1.010 & 1.000 & 1.000 & 3.346 \\
\hline & & 1st optimization stage & 1.100 & 2.999 & 0.990 & 1.001 & 0.990 & 0.130 & 2.760 \\
\hline \multirow[b]{2}{*}{4.} & \multirow{2}{*}{ 1PQ8 357-2PC } & Engineering & 1.000 & 3.000 & 0.990 & 1.010 & 1.000 & 1.000 & 0.703 \\
\hline & & 1st optimization stage & 1.100 & 3.000 & 0.999 & 1.000 & 0.120 & 0.010 & 0.540 \\
\hline \multirow[b]{2}{*}{5.} & \multirow{2}{*}{ 1PQ8 407-4PB } & Engineering & 1.000 & 3.000 & 0.990 & 1.010 & 1.000 & 1.000 & 0.790 \\
\hline & & 1st optimization stage & 1.099 & 2.993 & 0.999 & 1.000 & 0.130 & 0.010 & 0.640 \\
\hline \multirow[b]{2}{*}{6.} & \multirow[b]{2}{*}{ 1LA8 455-8AD } & Engineering & 1.000 & 3.000 & 0.990 & 1.010 & 1.000 & 1.000 & 9.113 \\
\hline & & 1st optimization stage & 1.100 & 3.000 & 0.990 & 1.010 & 1.000 & 0.990 & 8.560 \\
\hline \multirow[b]{2}{*}{7.} & \multirow{2}{*}{ 1LA8 458-4AD } & Engineering & 1.000 & 3.000 & 0.990 & 1.010 & 1.000 & 1.000 & 6.463 \\
\hline & & 1st optimization stage & 1.100 & 3.000 & 0.990 & 1.006 & 1.000 & 0.570 & 6.170 \\
\hline \multirow{2}{*}{8.} & \multirow{2}{*}{ 1PQ8 453-6PD } & Engineering & 1.000 & 3.000 & 0.990 & 1.010 & 1.000 & 1.000 & 5.779 \\
\hline & & 1st optimization stage & 1.100 & 3.000 & 0.990 & 1.005 & 1.000 & 0.500 & 5.340 \\
\hline \multirow{2}{*}{9.} & \multirow{2}{*}{ 1PQ8 458-8PD } & Engineering & 1.000 & 3.000 & 0.990 & 1.010 & 1.000 & 1.000 & 7.710 \\
\hline & & 1st optimization stage & 1.100 & 3.000 & 1.009 & 0.990 & 1.000 & 0.900 & 7.200 \\
\hline \multirow{2}{*}{10.} & \multirow{2}{*}{ 2A3M-2500/6000YXL4 } & Engineering & 1.000 & 3.000 & 0.990 & 1.010 & 1.000 & 1.000 & 0.274 \\
\hline & & 1st optimization stage & 1.048 & 2.692 & 1.000 & 1.000 & 0.000 & 0.000 & 0.010 \\
\hline
\end{tabular}

Applying the above optimization procedure to the motors listed in Table 1, the errors are significantly reduced, as shown in Table 2.

Table 2. Comparison between the Engineering Method and the 1st optimization stage. 
Based on the results in Table 2, $C_{1}$ is the most critical coefficient compared to $C_{2}-C_{4}$, which is due to the direct relation between cupper losses in the motor and $C_{1}$. Since the resistance of the stator in each unit is initially equal to the rated slip of the machine, correction is needed to satisfy the given efficiency of a machine. The results given in Table 2 show that the errors are reduced to almost zero for some machines after the first optimization stage (motors with numbers 1, 2, 4, 5 and 10) and decreased for other motors (numbers 3, 6, 7, 8 and 9); however, for these motors, the errors are still large. This leads to the second stage of optimization, as shown in Table 3.

In the second stage, the focus is to optimize the rotor parameters; rewriting (17)-(20) yields:

$$
\begin{gathered}
R_{r}^{(1)}=C_{5} \frac{G_{r}^{S_{\text {rated }}}}{\left(G_{r}^{S_{\text {rated }}}\right)^{2}+\left(B_{r}^{S_{\text {rated }}}\right)^{2}} S_{\text {rated }}, \\
x_{\sigma r}^{(1)}=C_{6} \frac{B_{r}^{S_{\text {rated }}}}{\left(G_{r}^{S_{\text {rated }}}\right)^{2}+\left(B_{r}^{S_{\text {rated }}}\right)^{2}} S_{\text {rated }} \\
R_{r}^{(2)}=C_{7} \frac{G_{r}^{(2)}}{\left(G_{r}^{(2)}\right)^{2}+\left(B_{r}^{(2)}\right)^{2}} \\
x_{\sigma r}^{(2)}=C_{8} \frac{B_{r}^{(2)}}{\left(G_{r}^{(2)}\right)^{2}+\left(B_{r}^{(2)}\right)^{2}}
\end{gathered}
$$

In this stage, the vector of the independent variables is:

$$
x=\left[\begin{array}{llll}
C_{5} & C_{6} & C_{7} & C_{8}
\end{array}\right]^{\prime}
$$

\begin{tabular}{|c|c|c|c|c|c|c|c|c|c|c|c|c|c|}
\hline \multirow{2}{*}{ No. } & \multirow{2}{*}{ Motor Type } & \multirow{2}{*}{ Method } & \multirow{2}{*}{$C_{1}$} & \multirow{2}{*}{$C_{2}$} & \multirow{2}{*}{$C_{3}$} & \multirow{2}{*}{$C_{4}$} & \multirow{2}{*}{$C_{5}$} & \multirow{2}{*}{$C_{6}$} & \multirow{2}{*}{$C_{7}$} & \multirow{2}{*}{$C_{8}$} & \multicolumn{3}{|c|}{ Error, \% } \\
\hline & & & & & & & & & & & $K_{i_{\text {start }}}$ & $K_{\mathbf{\Phi}_{\text {start }}}$ & $K_{\boldsymbol{\sigma}_{\max }}$ \\
\hline \multirow[b]{2}{*}{1.} & \multirow{2}{*}{ DAZO-1569-8/10 } & Engineering & 1.000 & 3.000 & 0.990 & 1.010 & 1.000 & 1.000 & 1.000 & 1.000 & 1.000 & 1.000 & 2.991 \\
\hline & & End optimization stage & 0.900 & 2.002 & 1.005 & 1.000 & 0.895 & 0.946 & 1.055 & 1.014 & 0.000 & 0.000 & 0.000 \\
\hline \multirow[b]{2}{*}{2.} & \multirow{2}{*}{ 1LA8 317-2AC } & Engineering & 1.000 & 3.000 & 0.990 & 1.010 & 1.000 & 1.000 & 1.000 & 1.000 & 1.000 & 1.000 & 1.007 \\
\hline & & 2nd optimization stage & 1.100 & 2.995 & 0.998 & 1.000 & 0.895 & 1.001 & 0.988 & 0.998 & 0.000 & 0.000 & 0.000 \\
\hline \multirow[b]{2}{*}{3.} & \multirow{2}{*}{ 1LA8 315-6AB } & Engineering & 1.000 & 3.000 & 0.990 & 1.010 & 1.000 & 1.000 & 1.000 & 1.000 & 1.000 & 1.000 & 3.346 \\
\hline & & 2nd optimization stage & 1.100 & 2.999 & 0.990 & 1.001 & 0.884 & 1.033 & 0.959 & 0.990 & 0.000 & 0.000 & 0.000 \\
\hline \multirow[b]{2}{*}{4.} & \multirow{2}{*}{ 1PQ8 357-2PC } & Engineering & 1.000 & 3.000 & 0.990 & 1.010 & 1.000 & 1.000 & 1.000 & 1.000 & 1.000 & 1.000 & 0.703 \\
\hline & & 2nd optimization stage & 1.100 & 3.000 & 0.999 & 1.000 & 0.899 & 0.998 & 0.995 & 1.000 & 0.000 & 0.000 & 0.000 \\
\hline \multirow[b]{2}{*}{5.} & \multirow{2}{*}{ 1PQ8 407-4PB } & Engineering & 1.000 & 3.000 & 0.990 & 1.010 & 1.000 & 1.000 & 1.000 & 1.000 & 1.000 & 1.000 & 0.790 \\
\hline & & 2nd optimization stage & 1.099 & 2.993 & 0.999 & 1.000 & 0.899 & 0.999 & 0.994 & 1.000 & 0.000 & 0.000 & 0.000 \\
\hline \multirow[b]{2}{*}{6.} & \multirow{2}{*}{ 1LA8 455-8AD } & Engineering & 1.000 & 3.000 & 0.990 & 1.010 & 1.000 & 1.000 & 1.000 & 1.000 & 1.000 & 1.000 & 9.113 \\
\hline & & 2nd optimization st & 1.100 & 3.000 & 0.990 & 1.010 & 0.833 & 1.133 & 0.947 & 0.977 & 0.000 & 0.000 & 0.000 \\
\hline \multirow[b]{2}{*}{7.} & \multirow{2}{*}{ 1LA8 458-4AD } & Engineering & 1.000 & 3.000 & 0.990 & 1.010 & 1.000 & 1.000 & 1.000 & 1.000 & 1.000 & 1.000 & 6.463 \\
\hline & & 2nd optimization stage & 1.100 & 3.000 & 0.990 & 1.006 & 0.868 & 1.090 & 0.946 & 0.973 & 0.000 & 0.000 & 0.000 \\
\hline \multirow[b]{2}{*}{8.} & \multirow[b]{2}{*}{ 1PQ8 453-6PD } & Engineering & 1.000 & 3.000 & 0.990 & 1.010 & 1.000 & 1.000 & 1.000 & 1.000 & 1.000 & 1.000 & 5.779 \\
\hline & & 2nd optimization stage & 1.100 & 3.000 & 0.990 & 1.005 & 0.864 & 1.076 & 0.948 & 0.976 & 0.000 & 0.000 & 0.000 \\
\hline \multirow[b]{2}{*}{9.} & \multirow{2}{*}{ 1PQ8 458-8PD } & Engineering & 1.000 & 3.000 & 0.990 & 1.010 & 1.000 & 1.000 & 1.000 & 1.000 & 1.000 & 1.000 & 7.710 \\
\hline & & 2nd optimization stage & 1.100 & 3.000 & 1.009 & 0.990 & 0.842 & 1.112 & 0.943 & 0.974 & 0.000 & 0.000 & 0.000 \\
\hline \multirow[b]{2}{*}{10} & & Engineering & 1.000 & 3.000 & 0.990 & 1.010 & 1.000 & 1.000 & 1.000 & 1.000 & 1.000 & 1.000 & 0.274 \\
\hline & 2А3M-2500/6000YXL4 & 2nd optimization stage & 1.048 & 2.692 & 1.000 & 1.000 & 0.894 & 0.987 & 1.000 & 1.000 & 0.000 & 0.000 & 0.000 \\
\hline
\end{tabular}

All the other parameters including $C_{1}, C_{2}, C_{3}$ and $C_{4}$ are kept constant after the first stage of optimization.

Table 3. Comparison between the results obtained by the engineering method and the 2nd optimization stage.

An unconstrained nonlinear programming optimization method based on the quasi-newton algorithm is used to solve the optimization problem with the same objective function as in (34), but without constraints imposed on the new $\mathrm{x}$ vector. The procedure of the second stage of optimization is summarized in Algorithm 2. 
Algorithm 2: Second Stage of Optimization.

Step 1: Import induction machine parameters from the manufacturer's data sheet

Step 2: Obtain the parameters of the equivalent circuit and the results of the first stage of optimization

Step 3: Keep $C_{1}, C_{2}, C_{3}$ and $C_{4}$ constants in the second stage of optimization

Step 4: Minimize the functions $f_{1}, f_{2}$ and $f_{3}$ with respect to the new variables: $C_{5}, C_{6}, C_{7}$ and $C_{8}$; and find their optimal values

Step 5: Recalculate the parameters of the equivalent circuit using the values of $C_{5}, C_{6}, C_{7}$ and $C_{8}$

\section{Results and Discussion}

The Engineering Method [17] and the two-stage optimization procedure proposed in Section 3 are programmed using MATLAB according to Algorithm 1 and 2. Table 4 shows the seven parameters of the equivalent circuit models determined by the Engineering Method and the two-stage optimization method for ten different induction motors. The results show that after the two-stage optimization, the errors in starting current, starting torque and pull-out torque are eliminated. The first stage optimization is targeted for the stator parameters, while the second stage, if necessary, aims at the optimization of the rotor parameters.

Figure 2 shows the torque- and current-slip characteristics of the induction motor number 10 in Table 4 as an example. It is clearly seen from Figure 2 that the characteristic curves are close to each other since the errors without optimization are within 1\%. Figure 3 shows the torque- and current-slip characteristic curves of the induction motor number 1 in Table 4 . It can be seen from Table 4 and Figure 3 that the errors without optimization are much greater than $1 \%$, but within $3 \%$. For motor number 1 , one stage of optimization is acceptable since the error is decreased to $1.02 \%$ after this optimization stage.

Table 4. Equivalent circuit model parameters determined by the engineering method and the two-stage optimization.

\begin{tabular}{|c|c|c|c|c|c|c|c|c|c|c|c|c|}
\hline \multirow{2}{*}{ No. } & \multirow{2}{*}{ Motor Type } & \multirow{2}{*}{ Method } & \multirow{2}{*}{$R_{s}$} & \multirow{2}{*}{$x_{œ e s}$} & \multirow{2}{*}{$x^{-}$} & \multirow{2}{*}{$R_{r}^{(1)}$} & \multirow{2}{*}{$x_{\mathbf{0 e r}}^{(\mathbf{1})}$} & \multirow{2}{*}{$R_{r}^{(2)}$} & \multirow{2}{*}{$x_{\mathbf{0 e r}}^{(2)}$} & \multicolumn{3}{|c|}{ Error, $\%$} \\
\hline & & & & & & & & & & $K_{i_{\text {start }}}$ & $K_{\mathbf{\emptyset}_{\text {start }}}$ & $K_{\mathbf{\sigma}_{\text {max }}}$ \\
\hline \multirow{6}{*}{1.} & \multirow{6}{*}{ DAZO-1569-8/10 } & Engineering method & 0.0093 & 0.061 & 2.429 & 0.0103 & 0.163 & 0.318 & 0.430 & 1.000 & 1.000 & 2.991 \\
\hline & & 1st opt. stage & 0.0084 & 0.091 & 2.391 & 0.0100 & 0.128 & 0.187 & 0.238 & 0.510 & 0.030 & 1.020 \\
\hline & & 2nd opt. stage & 0.0084 & 0.091 & 2.391 & 0.0090 & 0.121 & 0.245 & 0.249 & 0.000 & 0.000 & 0.000 \\
\hline & & Engineering method & 0.0070 & 0.048 & 3.173 & 0.0074 & 0.155 & 0.169 & 0.154 & 1.000 & 1.000 & 1.007 \\
\hline & & 1st opt. stage & 0.0077 & 0.048 & 3.186 & 0.0074 & 0.155 & 0.161 & 0.154 & 0.240 & 0.020 & 0.800 \\
\hline & & 2nd opt. stage & 0.0077 & 0.048 & 3.186 & 0.0066 & 0.155 & 0.159 & 0.152 & 0.000 & 0.000 & 0.000 \\
\hline \multirow{6}{*}{3.} & \multirow{6}{*}{ 1LA8 315-6AB } & Engineering method & 0.0110 & 0.051 & 2.671 & 0.0120 & 0.189 & 0.155 & 0.145 & 1.000 & 1.000 & 3.346 \\
\hline & & 1st opt. stage & 0.0121 & 0.051 & 2.683 & 0.0119 & 0.189 & 0.152 & 0.145 & 0.990 & 0.130 & 2.760 \\
\hline & & 2nd opt. stage & 0.0121 & 0.051 & 2.683 & 0.0106 & 0.195 & 0.139 & 0.141 & 0.000 & 0.000 & 0.000 \\
\hline & & Engineering method & 0.0060 & 0.051 & 3.363 & 0.0063 & 0.165 & 0.193 & 0.148 & 1.000 & 1.000 & 0.703 \\
\hline & & 1st opt. stage & 0.0066 & 0.051 & 3.376 & 0.0063 & 0.165 & 0.183 & 0.149 & 0.120 & 0.010 & 0.540 \\
\hline & & 2nd opt. stage & 0.0066 & 0.051 & 3.376 & 0.0057 & 0.165 & 0.183 & 0.148 & 0.000 & 0.000 & 0.000 \\
\hline \multirow{6}{*}{5.} & \multirow{6}{*}{ 1PQ8 407-4PB } & Engineering method & 0.0053 & 0.049 & 3.056 & 0.0057 & 0.161 & 0.177 & 0.142 & 1.000 & 1.000 & 0.790 \\
\hline & & 1st opt. stage & 0.0059 & 0.049 & 3.064 & 0.0057 & 0.162 & 0.169 & 0.143 & 0.130 & 0.010 & 0.640 \\
\hline & & 2nd opt. stage & 0.0059 & 0.049 & 3.064 & 0.0051 & 0.161 & 0.168 & 0.142 & 0.000 & 0.000 & 0.000 \\
\hline & & Engineering method & 0.0080 & 0.048 & 2.129 & 0.0093 & 0.187 & 0.083 & 0.193 & 1.000 & 1.000 & 9.113 \\
\hline & & 1st opt. & 0.0088 & 0.048 & 2.134 & 0.0093 & 0.188 & 0.082 & 0.191 & 1.000 & 0.990 & 8.560 \\
\hline & & 2nd opt. stage & 0.0088 & 0.048 & 2.134 & 0.0077 & 0.213 & 0.064 & 0.168 & 0.000 & 0.000 & 0.000 \\
\hline \multirow{6}{*}{7.} & \multirow{3}{*}{ 1LA8 458-4AD } & Engineering method & 0.0053 & 0.049 & 3.012 & 0.0057 & 0.180 & 0.083 & 0.215 & 1.000 & 1.000 & 6.463 \\
\hline & & 1st opt. stage & 0.0059 & 0.049 & 3.020 & 0.0057 & 0.181 & 0.083 & 0.214 & 1.000 & 0.570 & 6.170 \\
\hline & & 2nd opt. stage & 0.0059 & 0.049 & 3.020 & 0.0050 & 0.197 & 0.066 & 0.191 & 0.000 & 0.000 & 0.000 \\
\hline & \multirow{9}{*}{ 1PQ8 458-8PD } & Engineering method & 0.0080 & 0.051 & 2.477 & 0.0089 & 0.191 & 0.110 & 0.208 & 1.000 & 1.000 & 5.779 \\
\hline & & 1st opt. stage & 0.0088 & 0.051 & 2.484 & 0.0089 & 0.191 & 0.109 & 0.207 & 1.000 & 0.500 & 5.340 \\
\hline & & 2nd opt. stage & 0.0088 & 0.051 & 2.484 & 0.0077 & 0.206 & 0.091 & 0.189 & 0.000 & 0.000 & 0.000 \\
\hline \multirow{6}{*}{9.} & & Engineering method & 0.0080 & 0.051 & 2.168 & 0.0092 & 0.191 & 0.092 & 0.226 & 1.000 & 1.000 & 7.710 \\
\hline & & 1st opt. stage & 0.0088 & 0.051 & 2.173 & 0.0092 & 0.191 & 0.091 & 0.225 & 1.000 & 0.900 & 7.200 \\
\hline & & 2nd opt. stage & 0.0088 & 0.051 & 2.173 & 0.0077 & 0.213 & 0.071 & 0.197 & 0.000 & 0.000 & 0.000 \\
\hline & & Engineering method & 0.0083 & 0.063 & 4.557 & 0.0084 & 0.175 & 0.288 & 0.320 & 1.000 & 1.000 & 0.274 \\
\hline & & 1st opt. stage & 0.0087 & 0.070 & 4.569 & 0.0084 & 0.168 & 0.244 & 0.282 & 0.000 & 0.000 & 0.010 \\
\hline & & 2nd opt. stage & 0.0087 & 0.070 & 4.569 & 0.0075 & 0.165 & 0.257 & 0.280 & 0.000 & 0.000 & 0.000 \\
\hline
\end{tabular}




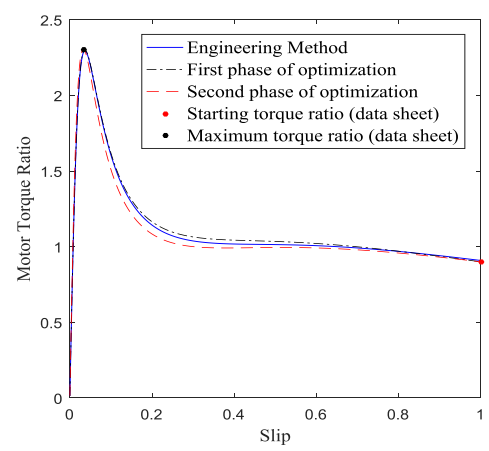

(a)

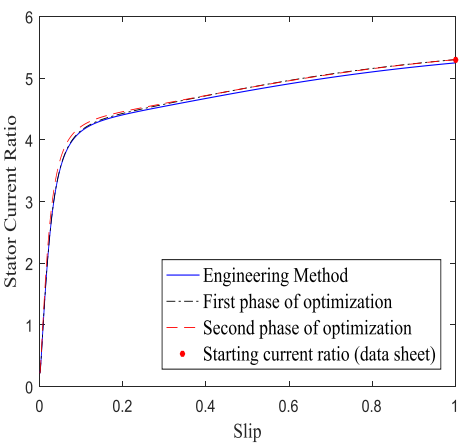

(b)

Figure 2. Characteristics of the induction motor number 10 (2A3M-2500/6000YXL4): (a) Torque-slip, (b) Current-slip.

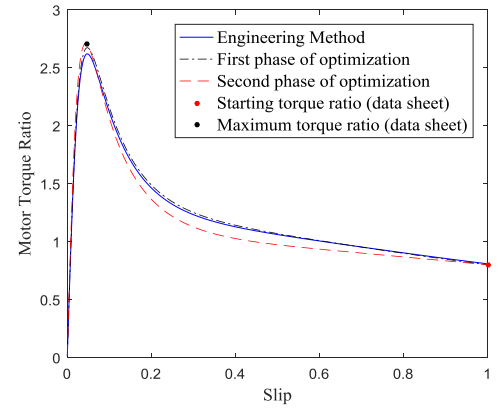

(a)

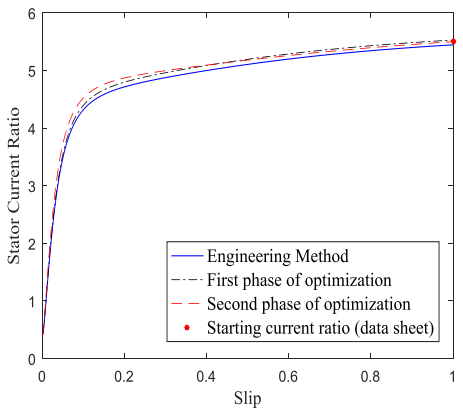

(b)

Figure 3. Characteristics of the induction motor number 1 (DAZO-1569-8/10): (a) Torque-slip, (b) Current-slip.

Figure 4 also shows the torque- and current-slip characteristics of the induction motor number 6 in Table 4. It is clear from Figure 4 and Table 4 that the errors are large without optimization and the two stages of optimization are then necessary. The results verified that the proposed two-stage optimization can effectively be used in tuning induction model parameters and eliminating the model output errors.

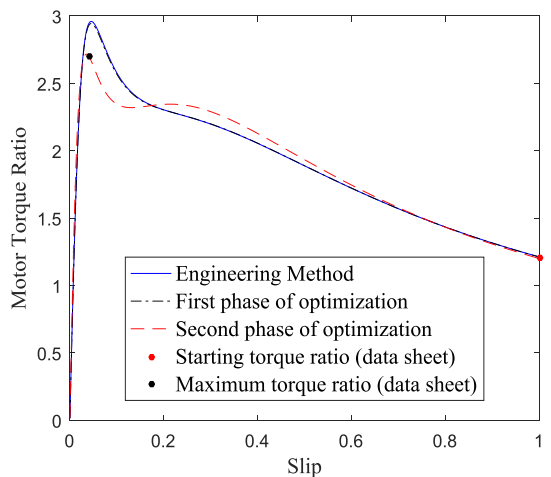

(a)

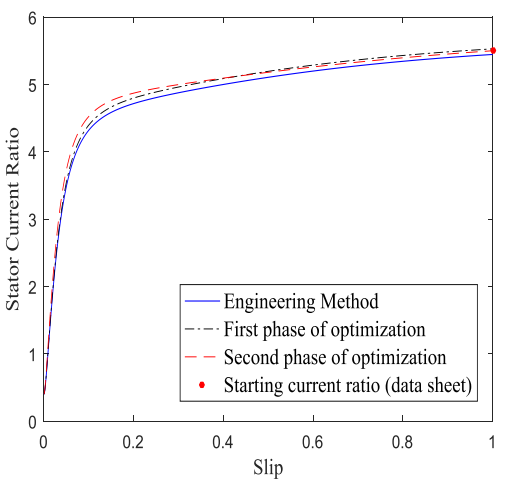

(b)

Figure 4. Characteristics of the induction motor number 6 (1LA8 455-8AD): (a) Torque-slip, (b) Current-slip.

The actual results obtained for ten induction motors were given and compared with the Engineering Method. The results show that the optimized parameters obtained via the two-stage optimization method well match the manufacturer's data, which successfully verified the effectiveness of the proposed parameter optimization method for induction motors. 


\section{Conclusions}

A two-stage optimization method was proposed for parameter estimation of the seven-parameter equivalent circuit model of three-phase induction motors. The optimization problem was formulated to minimize the objective function that is the sum of the errors between the calculated ratios of starting torque and current and pullout torque and the given values in the manufacturer's data sheet. The proposed method was compared with the Engineering Method used in industry. Although the Engineering Method is simple, the errors introduced by the method can be large for some induction motors.

The proposed two-stage optimization method has successfully addressed this issue via the two stages of parameter optimization: the first stage optimization on the stator parameters and the second stage optimization on the rotor parameters.

The Engineering Method can be applied for any of the three-phase squirrel-cage induction motors provided in the manufacturers' data. The nameplate data of the motor only is insufficient to apply this method and the proposed two-stage optimization.

Author Contributions: S.A.A.-J. and C.W. conceived the idea and supervised the implementation of the method; W.H.A. and S.A.A.-J. analyzed the data; W.H.A., S.A.A.-J. and C.W. wrote the paper.

Funding: The work of Caisheng Wang was partially supported by the National Science Foundation of USA under Grant ECCS-1508910.

Acknowledgments: Saleh A. Al-Jufout, Fulbright visiting scholar at Wayne State University, expresses his gratitude to Tafila Technical University and Wayne State University for facilitating his research visit.

Conflicts of Interest: The authors declare no conflict of interest.

\section{Nomenclature}

$R_{S} \quad$ Resistance of the stator, in per-unit (pu)

$x_{\sigma S} \quad$ Leakage inductance of the stator, pu

$S_{\text {rated }} \quad$ Rated slip of the machine

$K_{i_{\text {start }}} \quad$ Ratio of the starting current over the rated current

$\eta \quad$ Motor efficiency at full load

$\cos \phi \quad$ Power factor at full load

$\eta^{\prime} \quad$ Corrected value of efficiency

$\cos \phi^{\prime} \quad$ Corrected value of power factor

$x_{\mu} \quad$ Reactance of the magnetization branch, pu

$i_{\mu} \quad$ Magnetization current, pu

$K_{\tau_{\max }} \quad$ Ratio of the pullout torque to the full load torque

$K_{\tau_{\text {start }}} \quad$ Ratio of the starting torque to the full load torque

$G_{r}^{S_{\text {rated }}} \quad$ Conductance of the rotor, at the rated slip $\left(S_{\text {rated }}\right), \mathrm{pu}$

$B_{r}^{S_{\text {rated }}} \quad$ Susceptance of the rotor, at the rated slip $\left(S_{\text {rated }}\right)$, pu

$R_{r}^{(1)} \quad$ Resistance of the first rotor-circuit branch, pu

$x_{\sigma r}^{(1)} \quad$ Leakage reactance of the first rotor-circuit branch, pu

$R_{r}^{(2)} \quad$ Resistance of the second rotor-circuit, pu

$x_{\sigma r}^{(2)} \quad$ Leakage reactance of the second rotor-circuit, pu

$G_{r}^{(2)} \quad$ Conductance of the second rotor circuit, at starting slip ( $\left.=1\right)$, pu

$B_{r}^{(2)} \quad$ Susceptance of the second rotor circuit, at starting slip $(\mathrm{S}=1)$, pu

$S_{c r} \quad$ Critical slip, slip at maximum torque for a given induction machine

$K_{\tau_{\text {start }}^{c o r r}}^{\text {corr }} \quad$ Corrected starting torque ratio

$K_{i_{\text {start }}}^{c \text { corr }} \quad$ Corrected starting current ratio

$\lambda_{i}, i=1,2,3$ Weight factors for the error functions, for the optimization process

$C_{1}, C_{2}, \ldots C_{8} \quad$ Correction factors of the equivalent circuit parameters

$f_{i}, i=1,2,3 \quad$ Error functions between the calculated values and the real manufacturer values 


\section{Appendix}

Table A1. Technical specifications of the induction motors used in the analysis [17], [20] and [21].

\begin{tabular}{ccccccc}
\hline No. & Motor Type & $\begin{array}{c}\text { Output } \\
\text { Power, kW }\end{array}$ & $\begin{array}{c}\text { Rated } \\
\text { Voltage, V }\end{array}$ & $\begin{array}{c}\text { Rated } \\
\text { Current, A }\end{array}$ & $\begin{array}{c}\text { Rated } \\
\text { Speed, rpm }\end{array}$ & $\begin{array}{c}\text { Efficiency } \\
\text { \% }\end{array}$ \\
\hline 1 & DAZO-1569-8/10 & 800 & 6000 & 94 & 991 & 92.5 \\
2 & 1LA8 317-2AC & 315 & 415 & 504 & 2979 & 96.6 \\
3 & 1LA8 315-6AB & 200 & 415 & 338 & 989 & 95.7 \\
4 & 1PQ8 357-2PC & 500 & 415 & 797 & 2982 & 97.0 \\
5 & 1PQ8 407-4PB & 675 & 690 & 654 & 1492 & 690 \\
6 & 1LA8 455-8AD & 560 & 415 & 999 & 744 & 96.3 \\
7 & 1LA8 458-4AD & 1125 & 690 & 1103 & 1492 & 97.0 \\
8 & 1PQ8 453-6PD & 630 & 415 & 1080 & 992 & 96.6 \\
9 & 1PQ8 458-8PD & 670 & 690 & 717 & 744 & 96.5 \\
10 & 2A3M-2500/6000YXL4 & 2500 & 6000 & 260 & 2975 & 96.8 \\
\hline
\end{tabular}

\section{References}

1. Pustovetov, M.Yu. A mathematical model of the three-phase induction motor in three-phase stator reference frame describing electromagnetic and electromechanical processes. In Proceedings of the Dynamics of Systems, Mechanisms and Machines (Dynamics), Omsk, Russia, 11-13 November 2016; pp. 1-4.

2. Al-Jufout, S. Modelling of the cage induction motor for symmetrical and asymmetrical modes of operation. Comput. Electr. Eng. 2003, 29, 851-860. [CrossRef]

3. Asif, M.J.; Shahbaz, T.; Hassan, S.U.; Rizvi, S.T.H. Mathematical modelling of 3-phase induction motor to study the torque vs. speed characteristics using MATLAB Simulink. In Proceedings of the 19th International Multi-Topic Conference (INMIC), Islamabad, Pakistan, 5-6 December 2016; pp. 1-7.

4. Al-Jufout, S.; Khandakji, K. Dynamic simulation of starting and chopper speed control of wound-rotor induction motor. Int. J. Simul. Syst. Sci. Technol. 2007, 8, 1-7.

5. IEEE Standard Test Procedure for Polyphase Induction Motors and Generators, in IEEE Std. 112-2004 (Revision of IEEE Std 112-1996), pp.0_1-79, 2004.

6. Lee, K.; Frank, S.; Sen, P.K.; Polese, L.G.; Alahmad, M.; Waters, C. Estimation of induction motor equivalent circuit parameters from nameplate data. In Proceedings of the 2012 North American Power Symposium (NAPS), Champaign, IL, USA, 9-11 September 2012; pp. 1-6.

7. Natarajan, R.; Misra, V.K. Parameter estimation of induction motors using a spreadsheet program on a personal computer. Electr. Power Syst. Res. 1989, 16, 157-164. [CrossRef]

8. Haque, M.H. Estimation of three-phase induction motor parameters. Electr. Power Syst. 1993, 26, $187-193$. [CrossRef]

9. Boglietti, A.; Cavagnino, A.; Lazzari, M. Computational algorithms for induction-motor equivalent circuit parameter determination-Part I: Resistances and leakage reactances. IEEE Trans. Ind. Electr. 2011, 58, 3723-3733. [CrossRef]

10. Boglietti, A.; Cavagnino, A.; Lazzari, M. Computational algorithms for induction motor equivalent circuit parameter determination-Part II: Skin effect and magnetizing characteristics. IEEE Trans. Ind. Electr. 2011, 58, 3734-3740. [CrossRef]

11. Guimarães, J.M.C.; Bernardes, J.V.; Hermeto, A.E.; Bortoni, E.D.C. Parameter determination of asynchronous machines from manufacturer data sheet. IEEE Trans. Energy Convers. 2014, 29, 689-697. [CrossRef]

12. Haque, M.H. Determination of NEMA design induction motor parameters from manufacturer data. IEEE Trans. Energy Convers. 2008, 23, 997-1004. [CrossRef]

13. Gastli, A. Identification of induction motor equivalent circuit parameters using the single-phase test. IEEE Trans. Energy Convers. 1999, 14, 51-56. [CrossRef]

14. Boglietti, A.; Cavagnino, A.; Ferraris, L.; Lazzari, M. Skin effect experimental validations of induction motor squirrel cage parameters. In Proceedings of the 18th International Conference on Electrical Machines, Vilamoura, Portugal, 6-9 September 2008; pp. 1-4. [CrossRef] 
15. Lindenmeyer, D.; Dommel, H.W.; Moshref, A.; Kundur, P. An induction motor parameter estimation method. Electr. Power and Energy Syst. 2001, 23, 251-262. [CrossRef]

16. Pedra, J.; Corcoles, F. Estimation of induction motor double-cage model parameters from manufacturer data. IEEE Trans. Energy Convers. 2004, 19, 310-317. [CrossRef]

17. Sivokobylenko, V.F.; Kostenko, V. Electrical Motors Mathematical Modeling of the Power Station Auxiliaries. Donetsk Polytechnic Institute, 1979.

18. Sivokobylenko, V.F.; Tkachenko, S.N.; Derkachev, S.V. Determining the parameters of equivalent circuits and characteristics of induction motors. Elektrichestvo 2014, 10, 38-44.

19. Sivokobylenko, V.F. A hybrid equivalent circuit of asynchronous motors with a deep-slot or double-cage rotor. Elektrichestvo 2016, 4, 34-40.

20. Neklepaev, B.N.; Kruchkov, I.P. Electrical Part of Electrical Stations and Substations, Kiev, Ukraine. Energy 1987.

21. Reliability with Higher Efficiency; Large LV Motors Type 1LA8/1PQ8-(250 to 1250kW); Siemens, Thane, India, Technical Datasheet. August 2008. Available online: http:/ /w3.siemens.co.in/drives/in/en/motor/ ac-motor/Pages/N-compact-Series-Motors.aspx (accessed on 22 February 2017).

(C) 2018 by the authors. Licensee MDPI, Basel, Switzerland. This article is an open access article distributed under the terms and conditions of the Creative Commons Attribution (CC BY) license (http://creativecommons.org/licenses/by/4.0/). 